TAO, Vol. 15, No. 2, 239-259, June 2004

\title{
3-D Velocity Structure beneath the Chia-Nan Area, Taiwan
}

\author{
Strong Wen ${ }^{1, *}$ and Chau-Huei Chen ${ }^{1}$ \\ (Manuscript received 28 November 2003, in final form 5 May 2004)
}

\begin{abstract}
In this study, we adopt a damping least-square inversion method to investigate the $\mathrm{Vp}$ structures and $\mathrm{Vp} / \mathrm{Vs}$ ratios of the crust and upper mantle beneath the Chia-Nan area, Taiwan. Previous studies have shown that, velocity structure can be used as an indicator of the geometry of a fault and the general aspects of tectonics. Therefore, the first goal of this research is to analyze the degree of correlation between the velocity structure and the seismic characteristics with respect to the tectonic implications of the area. The second intention is to study the relationship between the $\mathrm{Vp} / \mathrm{Vs}$ ratio and the pressure change occurring with crack opening in the deeper crust. Finally, the distribution of $\mathrm{Vp} / \mathrm{Vs}$ ratios and its association with fault activities is also investigated.

Our results indicate that the variations in velocity structure beneath the Chia-Nan area is caused by local geological structures, fault crossing and the existence of the Pei-Kang High Area. We also find that most earthquakes occur in areas that have $\mathrm{Vp} / \mathrm{Vs}$ gradients varying rapidly. In addition, according to the distribution of the earthquakes, there seems to exist a westdipping fault west of the Chukou fault; however, this prospect needs to be investigated further in a future study.
\end{abstract}

(Key words: Damping least-square inversion method, VP, Vp/Vs ratios, Seismic characteristic)

\section{INTRODUCTION}

Taiwan is located at the convergent boundary of the Eurasian Plate and the Philippine Sea Plate. Taiwan is also recognized as a complex and tectonically active region (Suppe 1984; Ho 1986; Liu et al. 1997; Wu et al. 1997). There are roughly four thousand earthquakes occurring

\footnotetext{
${ }^{1}$ Institute of Seismology, National Chung Cheng University, Chiayi, Taiwan, ROC

* Corresponding author address.Dr. Strong Wen, Institute of Seismology, National Chung Cheng University, Chiayi, Taiwan, ROC; E-mail: strong@eq.ccu.edu.tw
} 
each year in Taiwan some of these can cause severe damage. According to several studies of earthquakes in Taiwan (Cheng et. al. 1998), there have been about one hundred destructive quakes during the $20^{\text {th }}$ century. Although most of the earthquakes occur in the eastern and northeastern seismic zones, the Chia-Nan Plain in southwestern Taiwan has been known as an area that produces many destructive earthquakes (e.g., Chia-Li 1991; Tapu 1993; Rei-Li 1998; Chia-Yi 1999). In order to have a better understanding of the characteristics of earthquakes occurring in the Chia-Nan area, it is very important to understand the velocity structures beneath the Chia-Nan Plain.

Owing to economic considerations for the development of the Chia-Nan area (see Fig. 1.), several major communication and transportation systems have been built in recent years. It is extremely important to analyze the accumulation of seismic energy in the upper crust; and to further investigate the possibility of a major earthquake occurring in this area. In this study, we will investigate the variations in velocity structure and their tectonic implications beneath the Chia-Nan area. We expect to provide useful information about the occurrence of hazardous earthquakes in the region.

The Taiwan Central Weather Bureau's Seismic Network (CWBSN) has set up seismic monitoring systems around Taiwan and its outlying islands. This dense seismic network and high precision three-component seismometers provided us with the high quality travel time records for $\mathrm{P}$ and $\mathrm{S}$ waves required for this study. Not only have we been able to analyze this data to determine earthquake locations precisely but we have also been able to obtain 3-D tomographic velocity structures beneath the Chia-Nan area. In addition to the Vp and Vs structures, we are also interested in studying the $\mathrm{Vp} / \mathrm{Vs}$ ratios. The ratio of $\mathrm{Vp} / \mathrm{Vs}$ reflects the rock porosity, the degree of fracture in the rock and the fluid pressure of the rock. But this ratio is affected by several factors, such as the composition of the rock, pore pressures, temperature, the direction of crack opening, and the level of fluid saturation in the rock. Therefore, the $\mathrm{Vp} / \mathrm{Vs}$ ratio is a key parameter in understanding the properties of crustal rocks (Christiansen 1996; Chen et. al. 2001). Recent studies have shown that the Vp/Vs ratios can also provide useful information about geological evolution and tectonic variations (Chen et. al. 2001).

Most earthquakes that occur in the active fault zone are accompanied by phenomena such as gusher well, soil liquefaction and sales. Thus $\mathrm{Vp} / \mathrm{Vs}$ ratios ought be useful in investigating the relationship between velocity structures and the degree of crack opening in associated rock. The crack opening of rock may be due to pressure changes within the rock causing gas to escape or fluid to migrate. This process makes the pore pressure larger, and it allows us to observe activities associated with fault formation and their association with the distribution of $\mathrm{Vp} / \mathrm{Vs}$ rations.

Direct observation of rock properties and pore pressure at hypocentral depth is difficult. 3-D seismic tomography provides us with some insights about the strength of crustal rock and the role of pore pressure in crustal dynamics. Several earlier studies have proved that the lateral variations of $\mathrm{Vp} / \mathrm{Vs}$ ratios are more sensitive to faulting properties than either a $\mathrm{Vp}$ or Vs structure is alone (Walck 1988; Thurber and Arte 1993; Musacchio et al. 1997; EberhartPhillips and Michael 1998; Graeber and Asch 1999; Gentile et al. 2000). There are studies on $\mathrm{Vp} / \mathrm{Vs}$ ratio structure in fault areas, which indicate high Poisson's ratios and low Vp structures. These findings suggest that over-pressured fluids exist in fault zones (Eberhart-Phillips and 
Michael 1993; John and McEvilly 1995; Thurber et al. 1997; Zhao and Negishi 1998). However, high Vp structures in source areas have also been found by some researches. This can be explained by the rigid parts of a fault zone (Eberhart-Phillips 1989; Lees and Nicholson 1993; Zhao and Kanamori 1995).

Several previous studies have focused on the 3-D tomographic velocity structure of the crust and mantle beneath the Taiwan area. A number of 3-D models of Vp structure have been proposed based on the study of seismic travel-time data (Roecker et al. 1987; Chen et al.1994; Rau and Wu 1995; Ma et al. 1996). These results provide large-scale velocity structure mappings. However the overall resolution is insufficient to describe the detailed velocity variations within the Chia-Nan area. In this research, one of our important objectives is to obtain a more precise 3 -D velocity structure beneath the Chia-Nan area and clarify some earlier findings. By using earthquake data from 1991 to 2000 recorded by CWBSN and applying tomographic inversion techniques, we have computed 3-D Vp and Vp/Vs models. Another intention is to investigate the spatial and temporal variations of the crustal velocity.

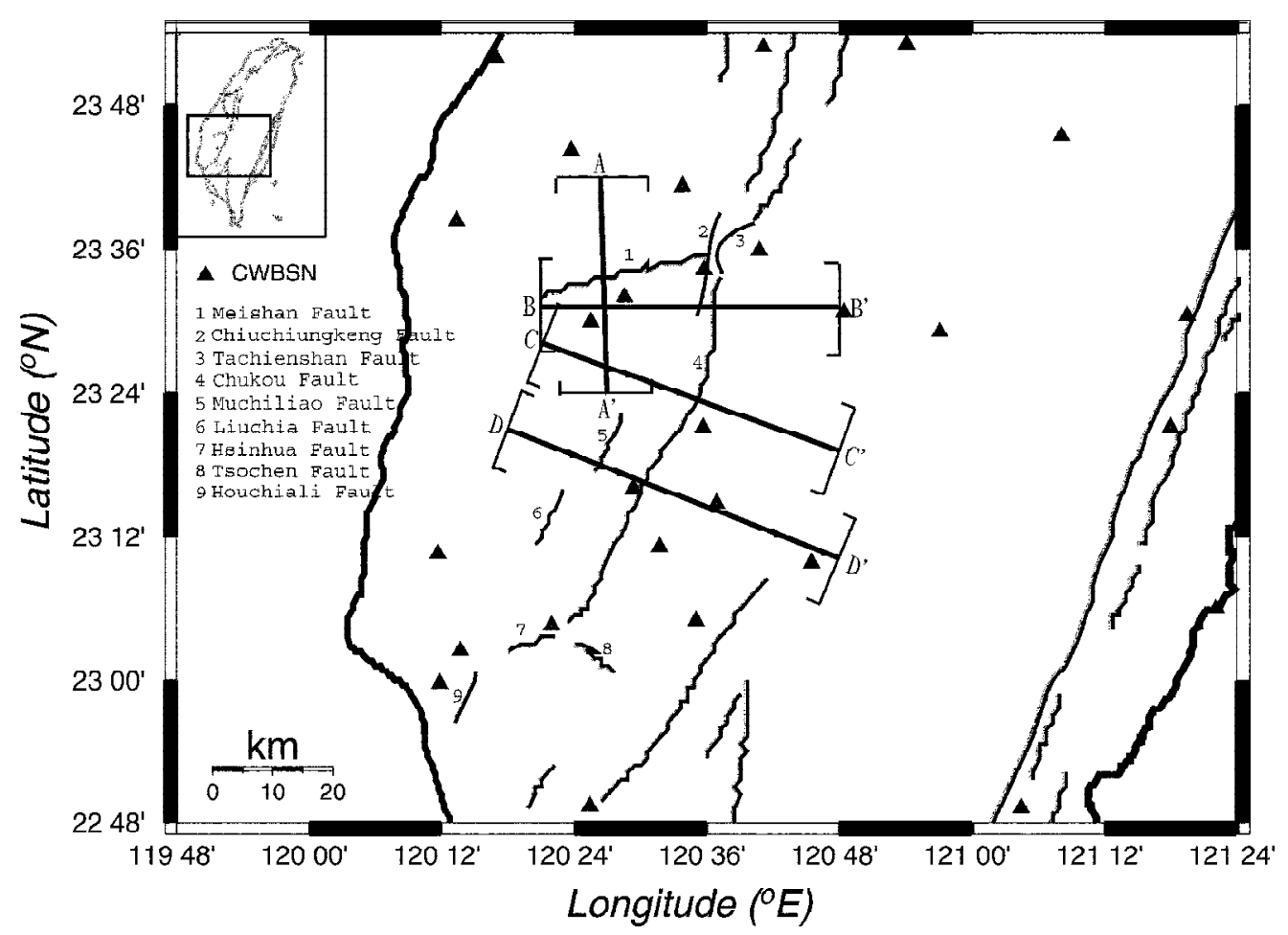

Fig. 1. The locations of the faults (denoted by number1-9) and the stations of CWBSN in our research area. The four lines represent the profiles AA', BB', CC' and DD' in this study. 


\section{GEOLOGICAL SETTING}

The Chia-Nan area can be divided into two predominant areas: the Western Foothills (WF) and the Western Coastal Plain (WCP). The WF are mainly composed of Neogene clastic sediments and part of the Oligocene strata. The dominant rock types are an interlamination of sandstone and shale. The thickness of the shale and mudstone layers increases from north to south. This main tectonic structure of the WF is a standard type of fold thrust belt. An obvious imbricate system composed of dense, unbalanced folds and low angle thrust faults dipping to the southeast. The surface of the system is about $10 \mathrm{~km}$ thick and covered with alluvium or laterite gravel. The deposition on the system is more flat than that in the eastern area nearer to the Central Mountain Range (CMR) (Ho 1986).

The outcrops of the WF include very complex folding structures, which consist of syncline, anticline and three major fault systems. Geologically, the properties of rock formation from the north to south and east to west change from being more rigid to loose, which could affect the velocity structure (Ho 1986). It is one of our more important goals to investigate the possibilities of this effect.

The Western Coastal Plain is covered with Quaternary diverse alluvial sediments that consist of marine sands and reworked beach materials. The alluvial deposits indicate tectonic uplift and denudation of the CMR as well as an erosion process.

\section{DATA}

This study uses the travel time data of $\mathrm{P}$ and $\mathrm{S}$ waves from the period January 1991 to May 2000 recorded by the CWBSN. A damping least-square inversion method was used to determine the $\mathrm{Vp}$ structure and $\mathrm{Vp} / \mathrm{Vs}$ ratio in the crust and upper mantle of the region. The programs and routines used to perform the 3-D inversion were originally developed by Thurber (1983), and have been modified by others to obtain both the $\mathrm{Vp}$ and $\mathrm{Vp} / \mathrm{Vs}$ ratio. This process saved solving for Vp and Vs individually (Evans et al. 1994; Eberhart-Phillips and Reyners 1997). As mentioned previously, the Vp/Vs ratio is directly related to the Possion Ratio which can be use to infer the petrological properties of crustal rocks. This parameter is also important in understanding the seismogenic behavior of the crust as well as the role of crustal fluids in the nucleation and growth of source rupture.

\subsection{Data Selection}

The latitude and longitude ranges of our study area are: $22.9^{\circ} \mathrm{N}-23.8^{\circ} \mathrm{N}$ and $120.1^{\circ} \mathrm{E}-121$. $4^{\circ} \mathrm{E}$. There are a lot of seismic events that have occurred in our research region. However, in order to have a uniform events distribution, we set some criteria to assist in selecting seismic data to improve the precision of the earthquake's epicenters determined by the Central Weather Bureau (CWB). The criteria is described as follow:

(1) Division of study area into two regions. The range for each region is:

a. Region $1: 22.9^{\circ} \mathrm{N}-23.8^{\circ} \mathrm{N}, 120.1^{\circ} \mathrm{E}-120.8^{\circ} \mathrm{E}$.

b. Region $2: 22.9^{\circ} \mathrm{N}-23.8^{\circ} \mathrm{N}, 120.8^{\circ} \mathrm{E}-121.4^{\circ} \mathrm{E}$. 
(2) Limitation of event magnitude for each region

a. Region 1: $\mathrm{M}_{\mathrm{L}} \geq 2.6$.

b. Region 2: $\mathrm{M}_{\mathrm{L}} \geq 4.5$. As region 2 was outside our study area, we needed to choose bigger events such that their seismic rays could reach the stations located in Chia-

Nan area. This ensured we had enough data to perform inversion.

A simultaneous inversion method technique was applied to the $\mathrm{P}$ and $\mathrm{S}$ waves travel-time data to derive reliable hypocenters and velocity structures. In order to improve the resolution of the tomographic inversion and uniform ray distribution around the volume source, we chose events with epicenter location errors less than $3 \mathrm{~km}$ and events with more than 6 readings of $P$ and $\mathrm{S}$ waves in the study area. To ensure the quality of the seismic data, the ERH and ERZ are less than $5 \mathrm{~km}$ and $10 \mathrm{~km}$ respectively. Under the above conditions, we were able to select 1,577 events with 24,925 $\mathrm{P}$-wave and 18,423 $\mathrm{S}$-wave arrival times to use in this study.

\subsection{Initial Velocity Model}

The reliability of the inversion results is dependent upon the initial reference model. We need an initial velocity structure that can best describe the structure beneath Chia-Nan area to perform a linear inversion. We chose an a priori 1-D P-velocity model parameterized by horizontal layers of constant velocities that could roughly reproduce the main features of the known velocity structure obtained by Chen et al. (1994; 1998) (see Fig. 2).

An uneven 3-D grid (see Fig. 3a) formed through a trial and error process parameterizes the 3-D structure. We also took several factors into account in the process: station spacing, estimated resolution and the desired spatial resolution around the fault plane. The initial $\mathrm{Vp} /$ Vs ratio was set to a constant value of 1.75 for the entire model and the damping of the velocity solution was determined by using the approach described in Eberhart-Phillips (1986). The effect of station elevation on the 3-D tomographic inversion was also considered in our calculation.

\section{RESULTS AND DISCUSSIONS}

In this section, we will discuss our results in two ways. The first section discusses the results in terms of how velocity structures and $\mathrm{Vp} / \mathrm{Vs}$ ratios were derived. This discussion will be accompanied by an examination of the resolution, standard error and the relative distribution of derivative weight sum (DWS). Here, the epicenters are relocated and velocity structures are calculated through the iterative process. Figure $3 \mathrm{~b}$ illustrates the comparison of epicenters before and after our relocation procedure. In Fig. 3b, an open circle indicates the relocated epicenters and the end of each thin line represents the epicenter before relocation. Our results show the locations of epicenters are clustered after relocation.

The second part of our discussion involves examining velocity structures in profile. In order to do this velocity structures beneath the Chia-Nan area, have been examined in four profiles across this area (see Fig. 1). These profiles are almost perpendicular to the Meishan and Chukou faults. Thus we can outline the relationship among the velocity structures, fault zones and seismicity. 


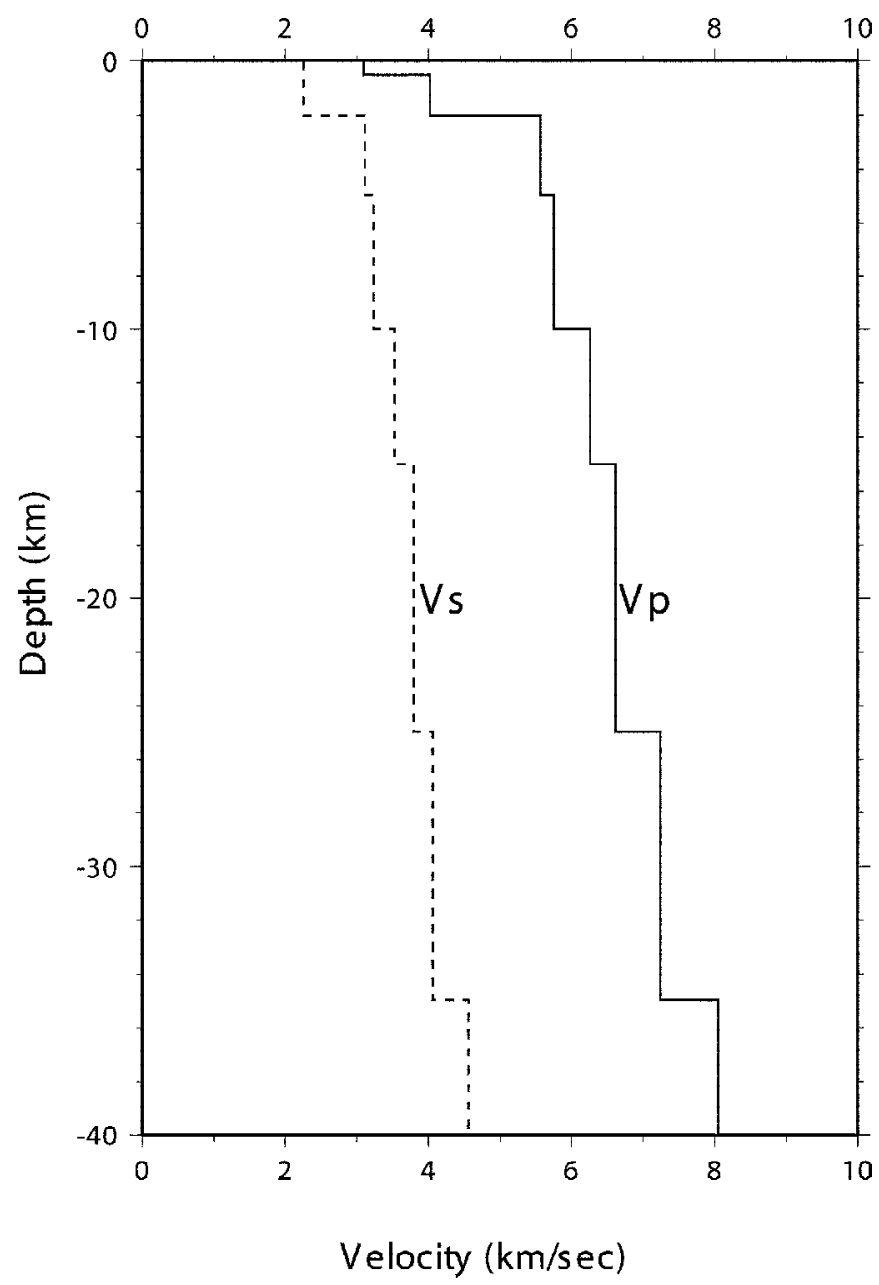

Fig. 2. The 1-D velocity model derived from Chen et. al. (1994).

\subsection{Resolution}

In our inversion study, a node is defined to be $12 \mathrm{~km} \times 6 \mathrm{~km}$ at the vicinity of the ChiaNan area center and increases in an outward direction to $15 \mathrm{~km} \times 10 \mathrm{~km}$ (see Fig. 3a). The thickness varies from $2 \mathrm{~km}$ at the surface to $10 \mathrm{~km}$ in the deeper crust. As the distributions of seismic events were observed conformably, the results show good resolution at the zones including the Chukou fault and in a band along the sides of the fault at about $15 \mathrm{~km}$ in width. However, resolution at a depth of 0 to $5 \mathrm{~km}$ and 25 to $35 \mathrm{~km}$ is relatively poor. At a depth of 0 to $5 \mathrm{~km}$, this problem may be due to the incident angles being almost perpendicular to the surface. Thus the lateral resolutions of velocity are lower. At a depth of 25 to $35 \mathrm{~km}$, a reason- 
able explanation may be that the selected events were few at a depth greater than $25 \mathrm{~km}$. In Figs. $4 a, b$, areas surrounded by black curves represent place where the value of resolution is larger than 0.6. These areas include the Chukou fault zone and especially its northeastern section. Such a high resolution indicates that the seismic rays crossed most of the area, and ought be reliable in helping determine the geology structures more precisely beneath the ChiaNan area.
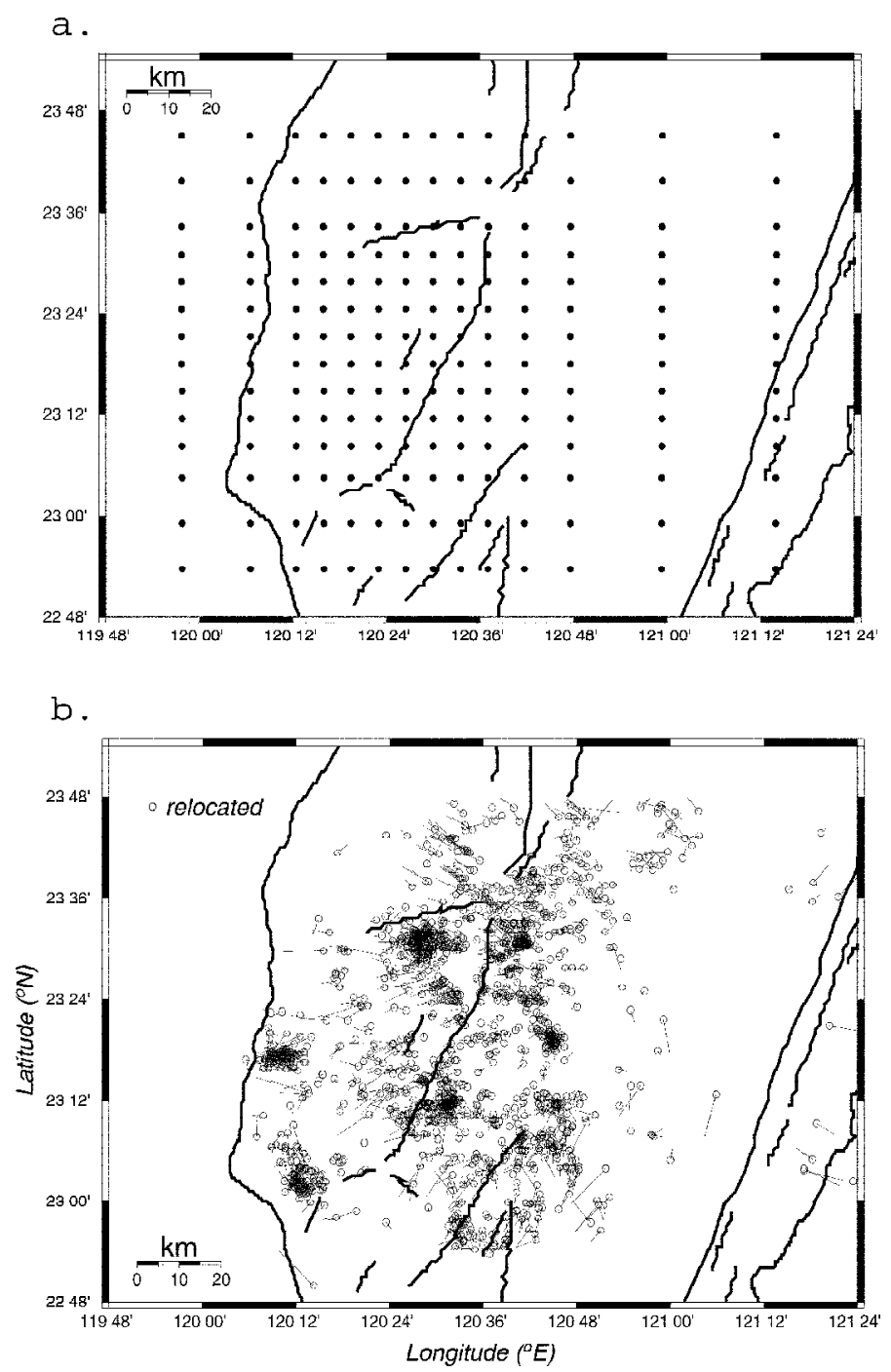

Fig. 3. (a) An uneven grid node distribution over our study area. (b) Epicenters after relocation in this study. Open circle indicate the relocated epicenters and at the end of each thin line represents the epicenter before relocation. 


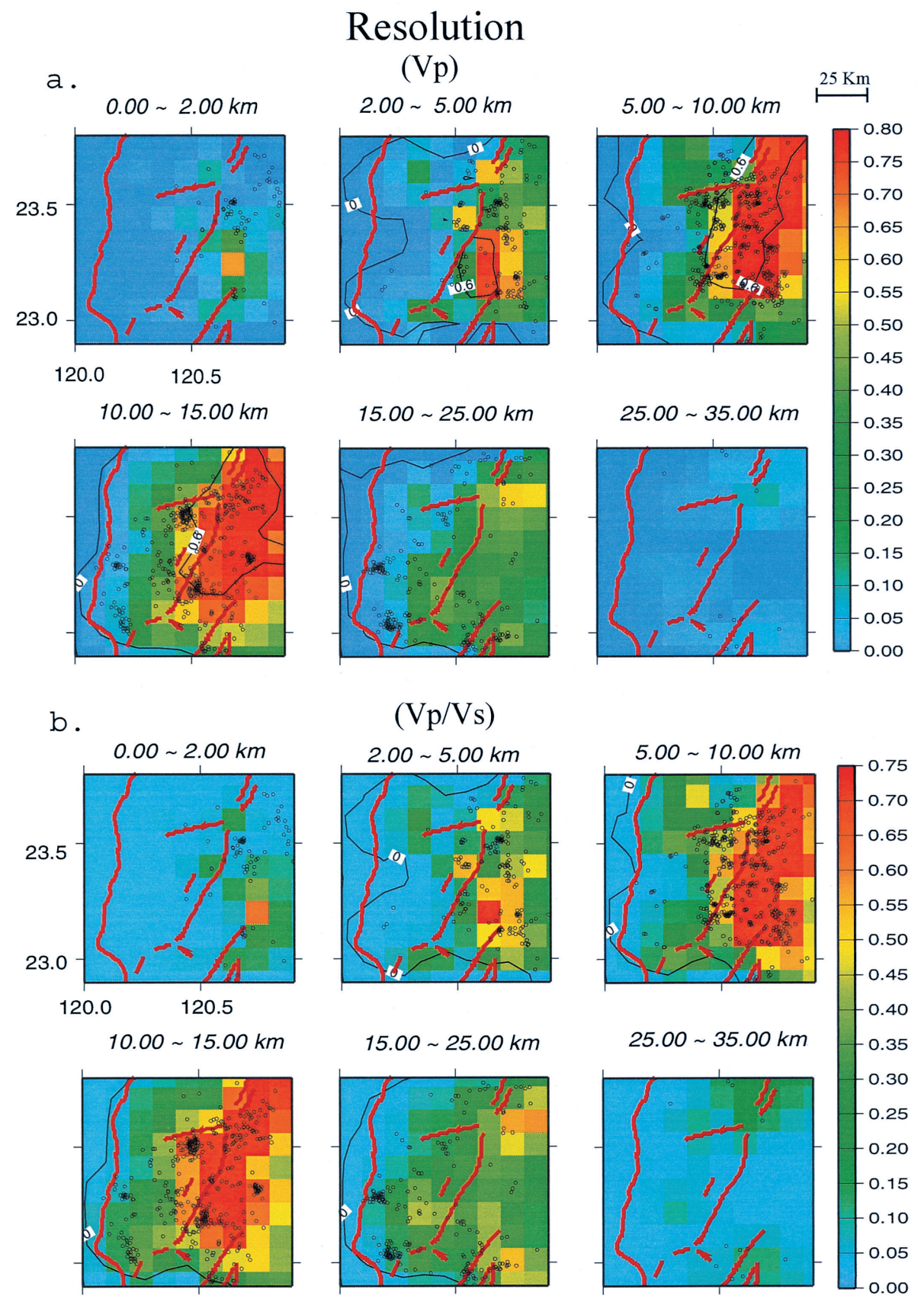

Fig. 4. (a) Distribution of resolution values for $\mathrm{Vp}$ in different depth ranges. Areas enclosed by black curve have resolution greater than 0.6. (b) Distribution of resolution values for $\mathrm{Vp} / \mathrm{Vs}$ in different depth ranges. Areas enclosed by black curve have resolution greater than 0.6. 


\subsection{Standard error}

In Fig. 5, the standard errors are relatively higher along the coastal zone and areas that have fewer seismic events. We observed that the standard error of $\mathrm{Vp}$ or the $\mathrm{Vp} / \mathrm{Vs}$ ratio increases with areas that have fewer events. However the error range in our study is reasonable and acceptable.

The distributions of seismic events were not observed conformably in each layer beneath the Chia-Nan area. However, there were fewer seismic clusters with low standard errors. The standard errors in the $\mathrm{Vp} / \mathrm{Vs}$ ratio are higher than in $\mathrm{Vp}$ (in general, the mean value is 1.7; the variation is 0.1 ). This may have been caused by fewer uncorrected travel times for $\mathrm{S}$ waves.

\subsection{The Derivative Weight Sum (DWS)}

In order to ensure the confidence level of our model, we not only use resolution and standard error to evaluate the quality of rays across our study area but also include the DWS. The DWS gives us a means of measuring the density of rays that pass near a grid point. It also can be used to estimate the distribution density of seismic ray paths and is adequate to resolve structural variations on the spatial scale defined by the nodal distances (Toomey and Foulger 1989). In Fig. 6 the areas enclosed by black curves are those with a ray density of more than 500 . At the depth of 5 to $25 \mathrm{~km}$, the DWS is high which implies that this area has a high confidence level. This phenomenon is obvious in the vicinity of Chukou fault to Meishan fault and especially the northern part of each fault.

\subsection{Velocity Structure}

In Fig. 7, the seismic events in each layer are numerous; however, most are located in the shallow layers at depths 5 to $25 \mathrm{~km}$. Therefore it is not possible to avoid the case that the seismicity is not uniform in our inversion process. The black thick curves in Fig. 7 are the contour lines of the DWS which are greater than 500. As the perturbations of $\mathrm{P}$ wave, most areas are negative. The results show that the initial values are larger than the inversion results.

At a depth 0 to $5 \mathrm{~km}$, the high and low values of Vp distribute dispersedly. We also observe that there exists scatter low $\mathrm{Vp}$ anomalies in the vicinity of the fault zone. At a depth of 5 to $15 \mathrm{~km}$, we find that low $\mathrm{Vp}$ anomalies increase with depth and expand in southwesterly direction. This may be associated with the existence of shallow sediment structures beneath this area (Ho 1986).

Since the age of rock formation is older near the CMR, the Vp becomes relatively high. In the south of the CMR, there exists a particular low Vp anomaly from 5 to $10 \mathrm{~km}$ (denoted by A, see Fig. 7a). But there is no anomaly in its upper and lower layers. We believe that this anomaly is caused by different rock properties. There are several cluster events existing in each layer and most lay within low $\mathrm{Vp}$ anomalies.

$\mathrm{The} \mathrm{Vp} / \mathrm{Vs}$ ratio is related to the composition of rock, porosity, fluid pressure, and degree of fracture. Fluid saturation, temperature, and the directions of fracture arrangement and core pressure also affect it (Walck 1988). These factors have significant effect on Vp/Vs ratio in 


\section{Standard Error}

$(\mathrm{Vp})$
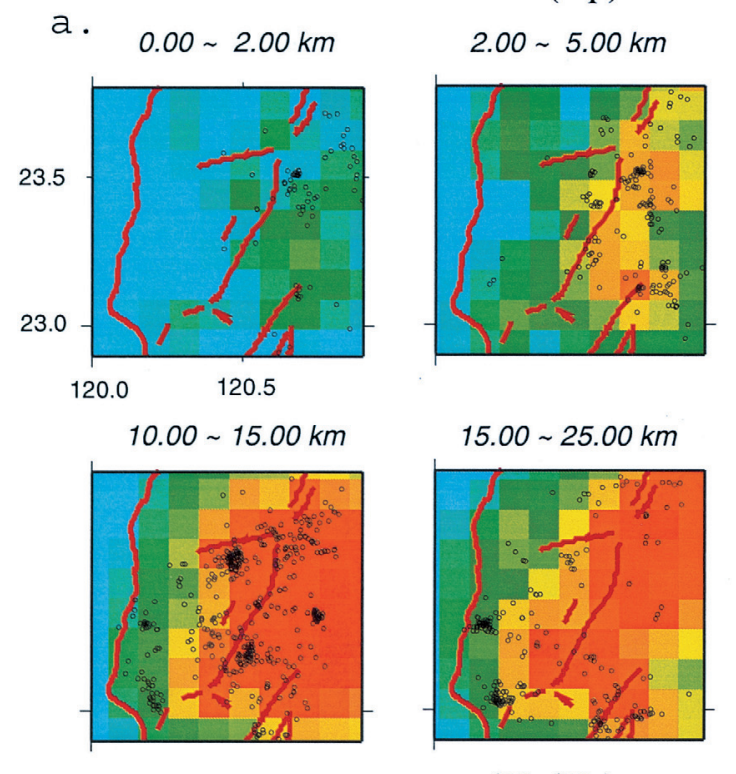

$5.00 \sim 10.00 \mathrm{~km}$

b.
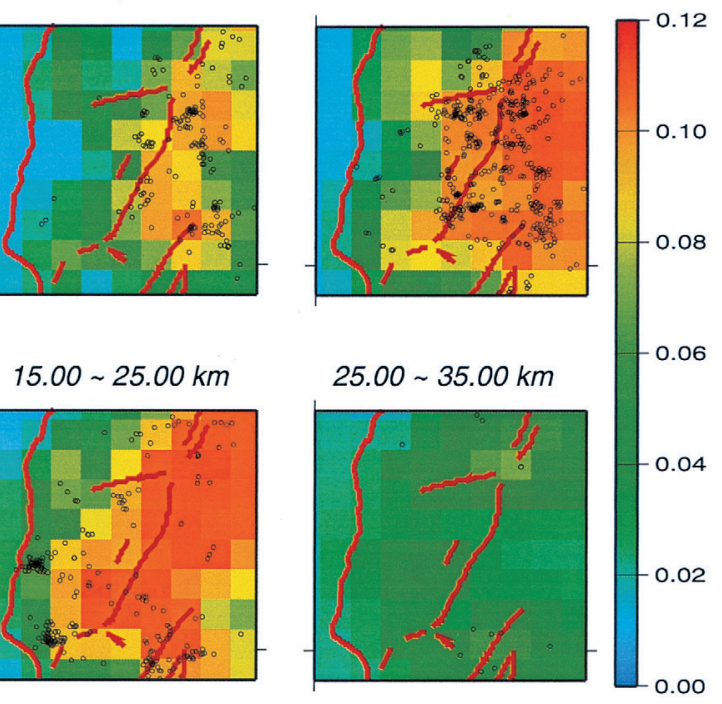

$(\mathrm{Vp} / \mathrm{Vs})$
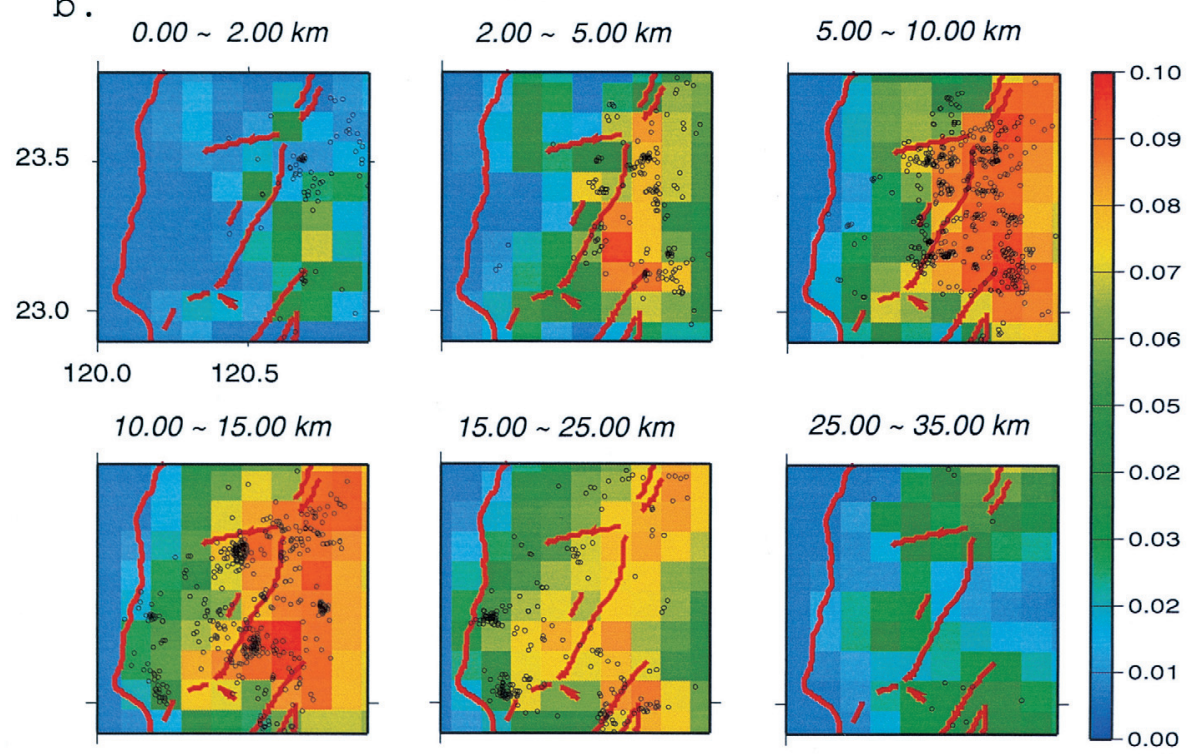

Fig. 5. (a) Distribution of standard error values for $\mathrm{Vp}$ in different depth range. (b) Distribution of standard error values for $\mathrm{Vp} / \mathrm{Vs}$ in different depth range. The standard errors in $\mathrm{Vp} / \mathrm{Vs}$ ratio are more higher than in $\mathrm{Vp}$ (in general, the mean value is 1.7 ; the variation is 0.1 ). 


\section{DWS}

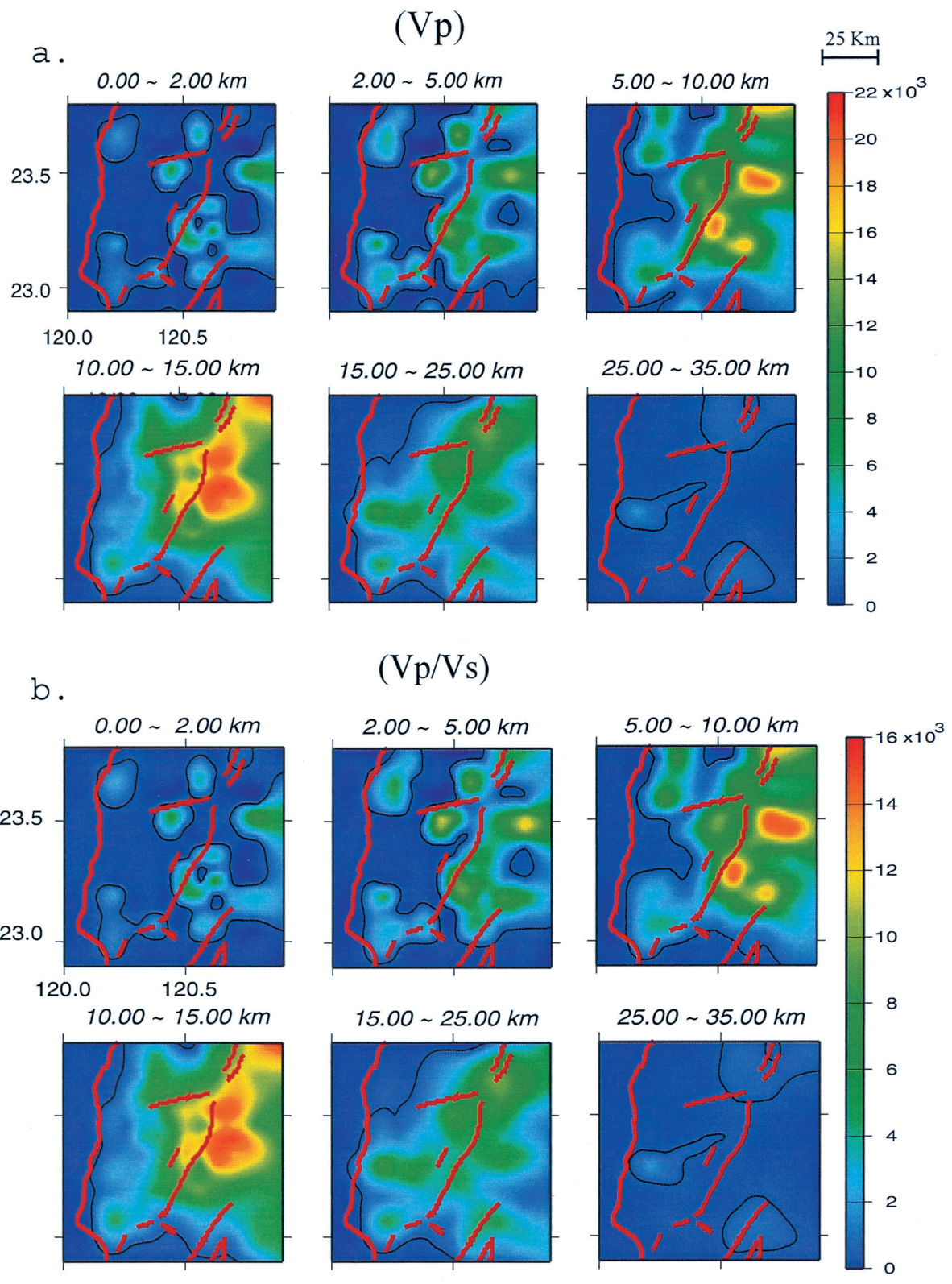

Fig. 6. (a) Distribution of derivative weight sum (DWS) values Vp in different depths. (b) Distribution of derivative weight sum (DWS) values for $\mathrm{Vp} / \mathrm{Vs}$ ratio in different depths. Black DWS contours encircle regions of adequate resolution for different depths. 


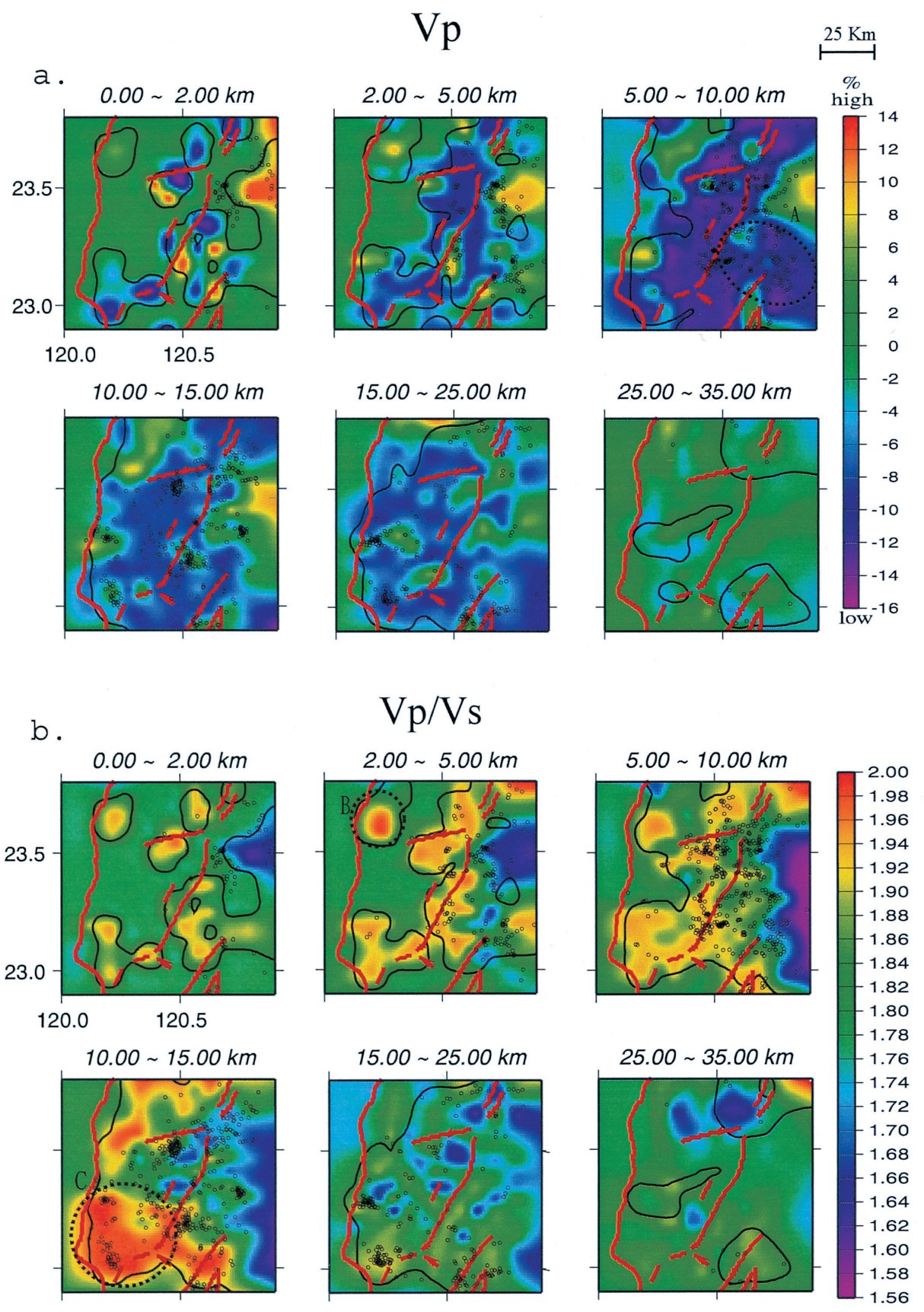

Fig. 7. (a) 3-D tomographic Vp structure at six depth ranges $(0-2 \mathrm{~km}, 2-5 \mathrm{~km}$, 5-10 km, 10-15 km, 15-25 km, 25-35 km). (b) 3-D tomographic Vp/Vs ratio at six depth ranges. 
shallow layers. However in deeper layers, the pressure increases and most fractures begin to close (Thurber et al. 1993), and the effect of the other factors above declines markedly.

In the vicinity of fault zones, a high $\mathrm{Vp} / \mathrm{Vs}$ ratio anomaly is due to pore pressure increases and thus decreases in the $\mathrm{S}$ wave velocity. We also observe that a high $\mathrm{Vp} / \mathrm{Vs}$ ratio anomaly broadened from the Western Foothills to the Western Coastal Plain between 0 to $15 \mathrm{~km}$. The distribution of high and low anomalies reflects the lack of homogeneity of velocity structures beneath the surface.

We also find that the low $\mathrm{Vp} / \mathrm{Vs}$ ratio zone extends to the CMR with increasing depth (see Fig. 7b). The reason likely being that rock formations are older and denser beneath the CMR, which contain less fluid or $\mathrm{SiO} 2$, and this leads to the $\mathrm{Vp} / \mathrm{Vs}$ ratio becoming lower. In this area, the high $\mathrm{Vp} / \mathrm{Vs}$ anomaly broadens to $15 \mathrm{~km}$ at depth. This high anomaly is more obvious from 0 to $15 \mathrm{~km}$.

Our results indicate that most seismic events are located in the areas having $\mathrm{Vp} / \mathrm{Vs}$ gradients that vary greatly or that have a high $\mathrm{Vp} / \mathrm{Vs}$ ratio. The $\mathrm{Vp} / \mathrm{Vs}$ anomaly (denoted as $\mathrm{B}$ ) becomes higher as the depth increases, however, at a depth of $10 \mathrm{~km}$, it becomes normal. The phenomenon is related to high Vp structures beneath the Pei-Kang high area. Another high $\mathrm{Vp} / \mathrm{Vs}$ anomaly (denoted by $\mathrm{C}$ in Fig. 7a) extends down $15 \mathrm{~km}$ from the surface.

\subsection{Vertical Profiles}

We chose four profiles of the same length $(16 \mathrm{~km})$, but with varying widths. The range includes the Tachienshan fault, Chukou fault, Meishan fault, Hsinhua fault and Houchiali fault. For each profile, we will discuss seismicity as well as the tectonic implications and variations.

\section{Profile AA'}

The strike of profile AA' is in the north-south direction and across the Meishan fault (MSF) see Fig. 8. The dip angle of the MSF is about 82 degrees (Wang and Chen 2001). The total length of AA' is about $33 \mathrm{~km}$. Most shallow events exist in this area and concentrate with the underline of the MSF. Along the sides of the MSF, velocity increases from north to south. There exists a low Vp anomaly in the northern area at a depth of 5 to $15 \mathrm{~km}$. This anomaly is related to the existence of shallow sediment structures. Along the direction of the fault dip, the gradients of $\mathrm{Vp} / \mathrm{Vs}$ vary greatly. At a depth of about $10 \mathrm{~km}$, there exists a high $\mathrm{Vp} / \mathrm{Vs}$ anomaly, it indicates that this area is fluid-filled at the crack opening and leads to an $\mathrm{S}$ wave velocity decrease, therefore the $\mathrm{Vp} / \mathrm{Vs}$ ratio increases. Our results are similar to the study of the Chelungpu fault (Chen et al. 2001).

\section{Profile BB'}

In Fig. 9, BB' profiles across the Chukou fault (CKF) perpendicular from west to east. Figure 9 shows the location of the CKF and its dip angle at about 30 degrees (Wang and Chen 2001). As with the AA' profile, the velocity structures increase from east to west on the two sides of the CKF. This area is near the Central Mountain Range and the rock formation is metamorphic, which leads to relatively high $\mathrm{P}$ wave velocities. The seismicity along the dip 


\section{Profile--AA'}
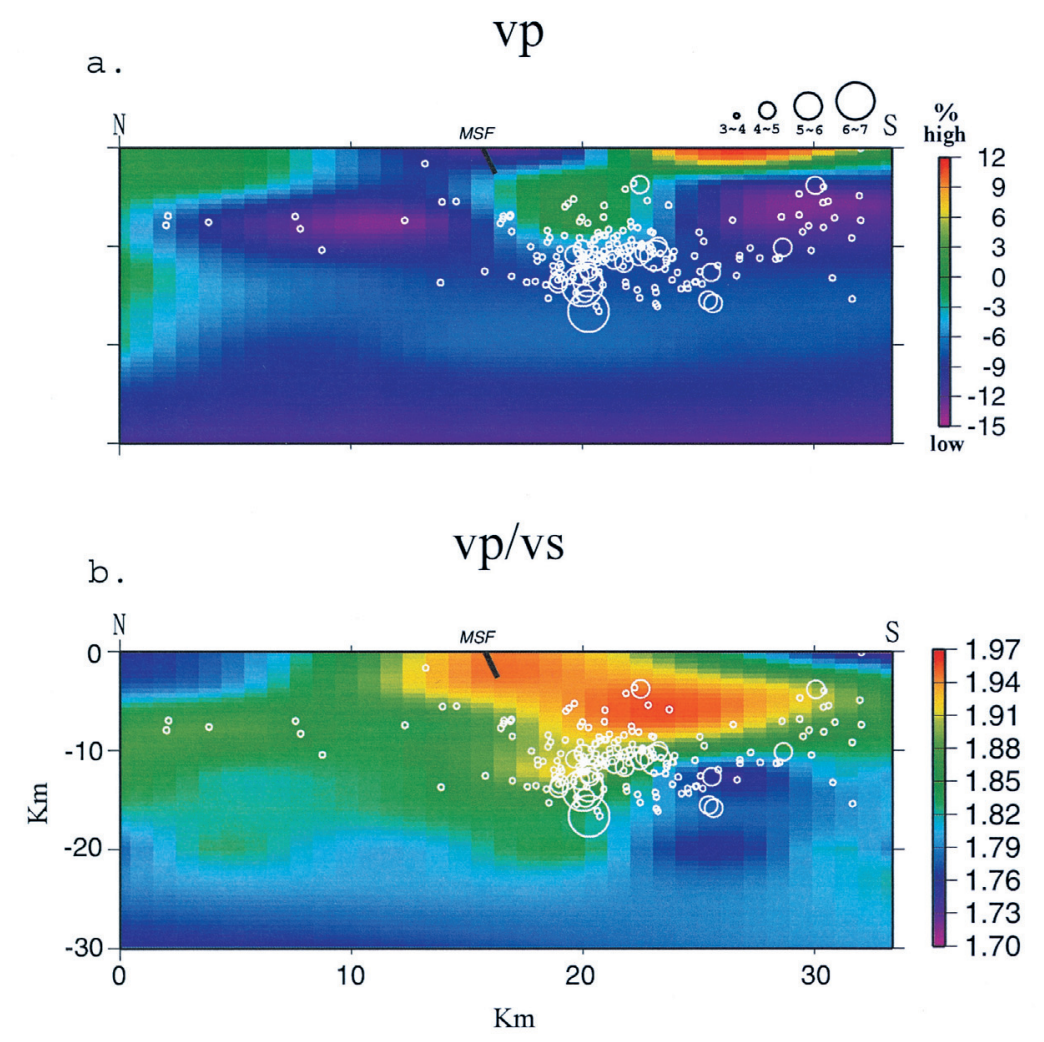

Fig. 8. (a) Tomographic Vp structure along the profile AA'. Circles represent event used in inversion for this profile. MSF indicates the location of Mei-shan fault. Note: the Vp values are shown by percentages of the differences with respect to the 1-D model. (b) Tomographic Vp/Vs ratio structure along the profile $\mathrm{AA}^{\prime}$. Circles represent event used in inversion for this profile.

direction between depths 5 to $20 \mathrm{~km}$ of the CKF indicates an obvious seismic zone (denoted by A in Fig. 9b). This dips to the west in the western part of the CKF and includes several shallow events of magnitude greater than 6 . This group of events exists in the zone where the gradient of $\mathrm{Vp} / \mathrm{Vs}$ varies greatly, and we believe that this is a blind fault zone regarding geological implications. In addition, there exists a high $\mathrm{Vp}$ anomaly in the west of the BB' profile. The low $\mathrm{Vp} / \mathrm{Vs}$ anomaly beneath the CMR still exists and its range is larger than in the AA' profile. The edge of the anomaly locates along the dipping plane of the CKF. Along the direction of the CKF dipping angle, the high $\mathrm{Vp} / \mathrm{Vs}$ anomaly that dips to east was related to the CMR and the seismic zone that dips to the west occurrs in the boundary of high $\mathrm{Vp} / \mathrm{Vs}$ anomaly. 


\section{Profile--BB'}
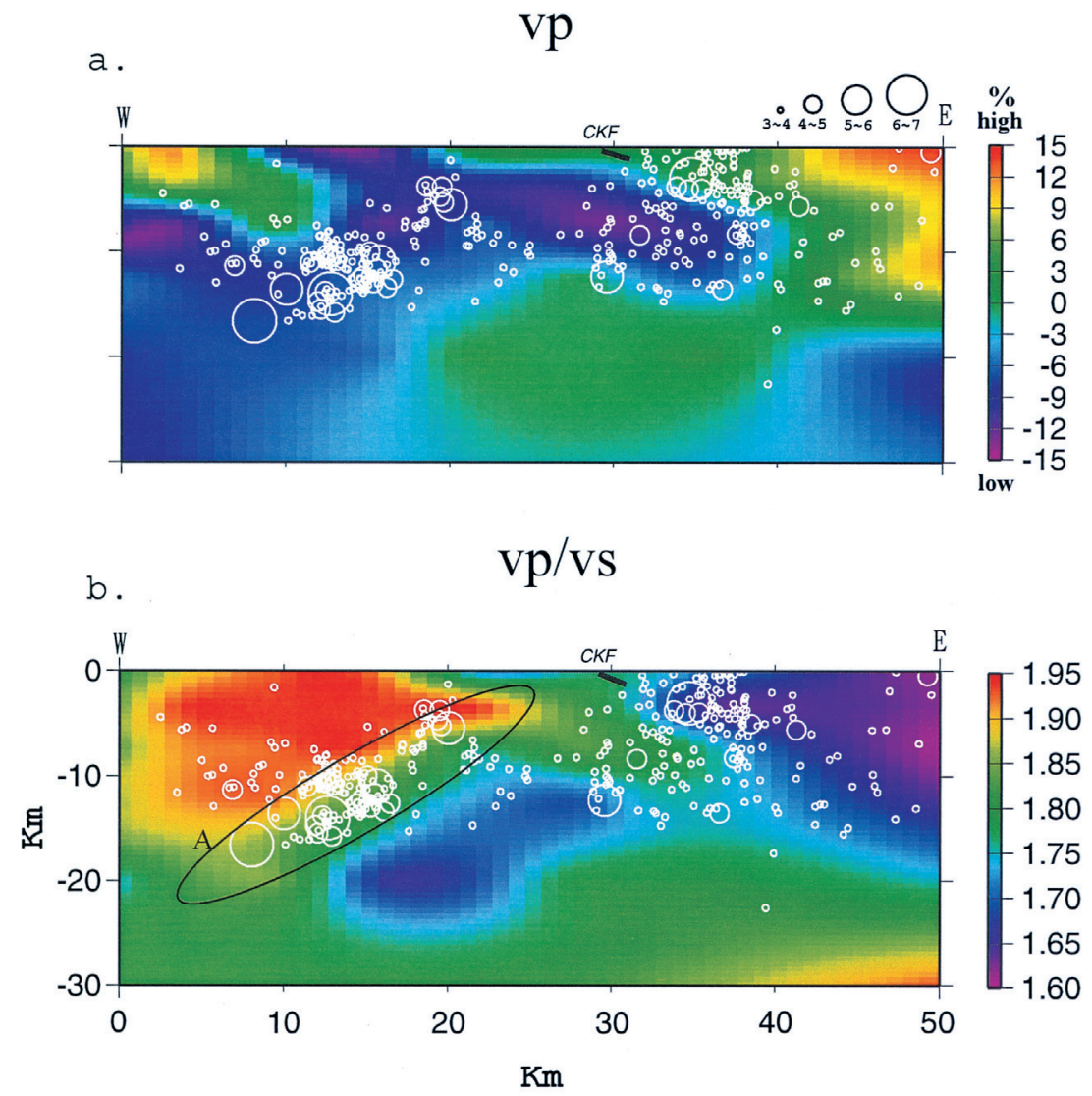

Fig. 9. (a) Tomographic Vp structure along the profile BB'. Circles represent event used in inversion for this profile. CKF indicates the location of Chukou fault. Note: the Vp values are shown by percentages of the differences with respect to the 1-D model. (b) Tomographic Vp/Vs ratio structure along the profile BB'. Circles represent event used in inversion for this profile.

\section{Profile CC'}

In Fig. 10, profile $\mathrm{CC}^{\prime}$ also crosses the $\mathrm{CKF}$ and its strike is in a northwesterly direction. However, numerous events do not locate uniformly and most locate above $20 \mathrm{~km}$. Beneath the profile, although the perturbation of $\mathrm{Vp}$ is smooth, high and low velocity zones can still be seen across the CKF. Between depths 5 to $30 \mathrm{~km}$, no particularly high anomaly exists. However, there is linear seismicity that distributes and dips to the west. An obvious boundary beneath 


\section{Profile--C $C^{\prime}$}
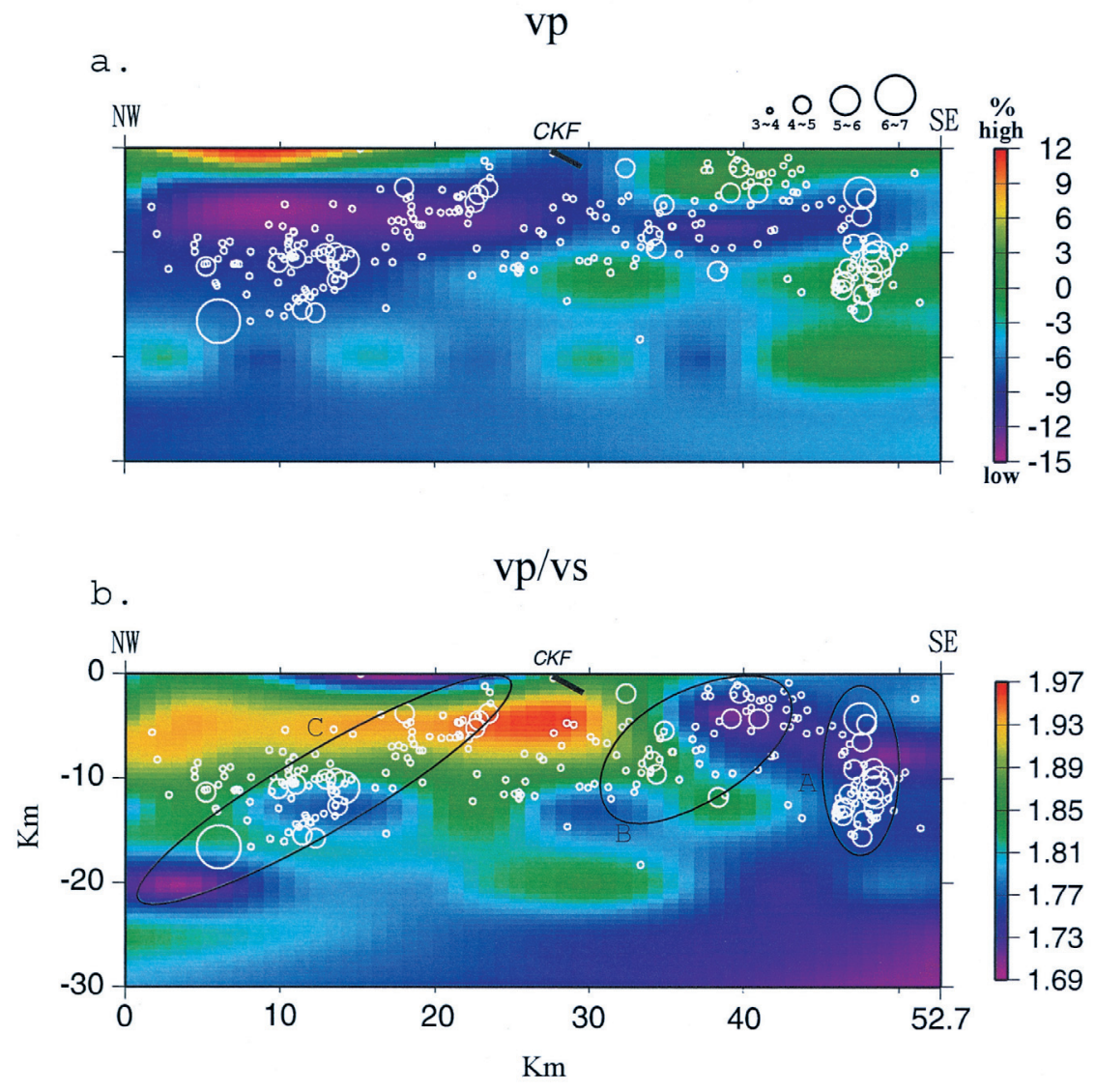

Fig. 10. (a) Tomographic Vp structure along the profile CC'. Circles represent event used in inversion for this profile. CKF indicates the location of Chukou fault. Note: the Vp values are shown by percentages of the differences with respect to the 1-D model. (b) Tomographic Vp/Vs ratio structure along the profile $\mathrm{CC}^{\prime}$. Circles represent event used in inversion for this profile.

the CKF separates high $\mathrm{Vp} / \mathrm{Vs}$ in the west and low $\mathrm{Vp} / \mathrm{Vs}$ in the eastern zones. There are two earthquake groups that exist in the eastern section denoted by A, B in Fig. 10; the seismicity disperses beneath the CKF and exhibits a linear series in the western section. It is also possible to observe high $\mathrm{Vp} / \mathrm{Vs}$ anomaly in profile $\mathrm{CC}^{\prime}$ as an extension of the $\mathrm{Vp} / \mathrm{Vs}$ anomaly in profile $\mathrm{BB}$. 


\section{Profile DD'}

In Fig. 11, profile DD' crosses the Chukou fault (CKF), and Muchiliao fault (MCF); both are thrust faults. The DD' profile is almost perpendicular to the faults with strike in a northeasterly direction. We observed that the $\mathrm{P}$ wave velocity is high in the east and low in the west above the fault zones. However, below the fault zones, the seismicity seems parallel with the velocity structures and most events occurred in the zones that have low $\mathrm{P}$ wave velocity. From

\section{Profile--DD'}
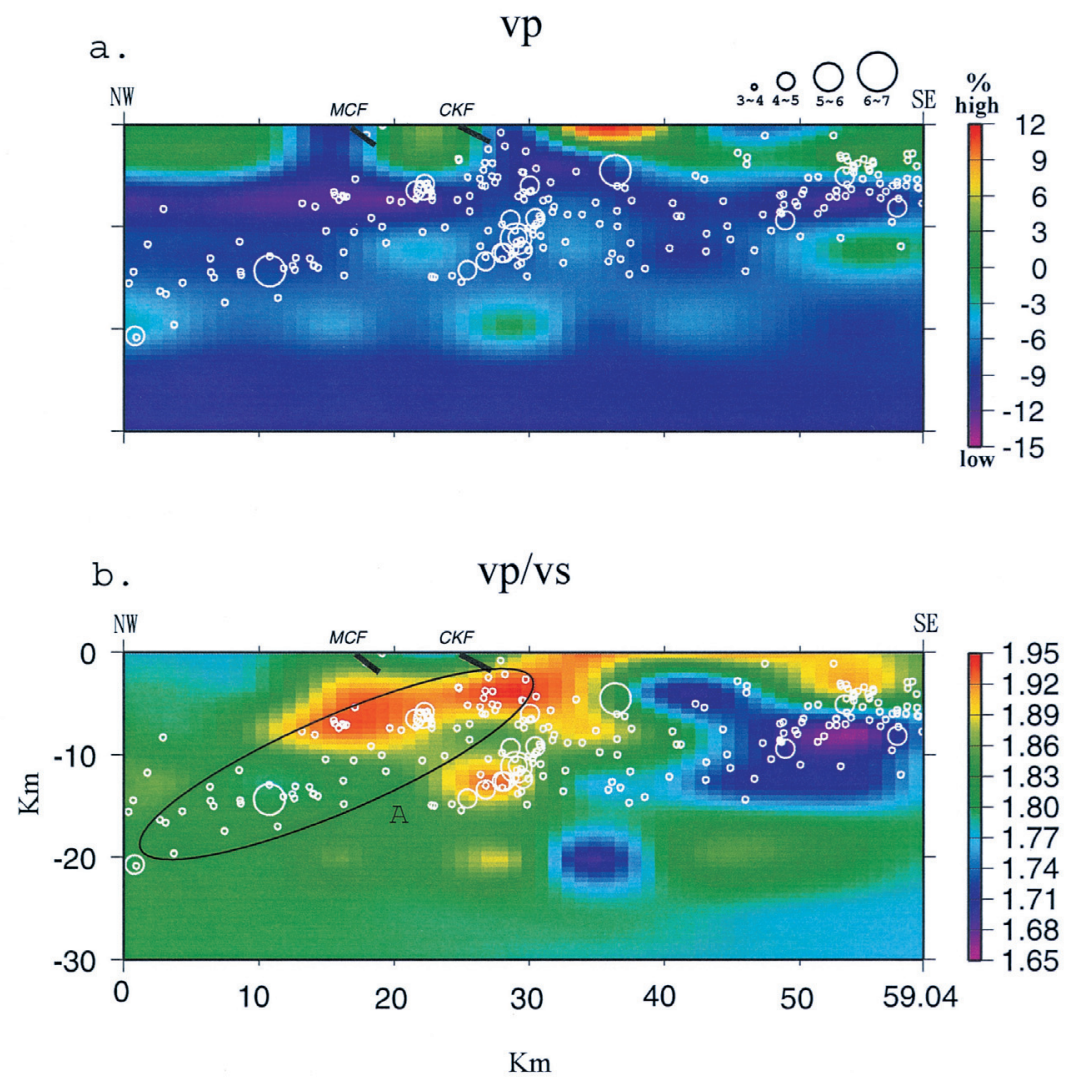

Fig. 11. (a) Tomographic Vp structure along the profile DD'. Circles represent event used in inversion for this profile. MCF indicates the location of Muchiliao fault. Note: the Vp values are shown by percentages of the differences with respect to the 1-D model. (b) Tomographic Vp/Vs ratio structure along the profile DD'. Circles represent event used in inversion for this profile. 
the extension of profile CC', the CKF and MCF cross a high $\mathrm{Vp} / \mathrm{Vs}$ anomaly zone and the seismicity also exhibits a linear series (denoted by A). There also exist events clustered below A. In addition there also exist high $\mathrm{Vp} / \mathrm{Vs}$ anomaly below the fault zones from the extension of high $\mathrm{Vp} / \mathrm{Vs}$ anomaly zones in profile BB' and CC'. Seismicity exists in zones where the gradient of $\mathrm{Vp} / \mathrm{Vs}$ varies greatly in the eastern section, but the same conditions are not as obvious in the western part.

We conclude that high seismicity exists in zones that exhibit low $\mathrm{P}$ wave velocity and where the $\mathrm{Vp} / \mathrm{Vs}$ ratio gradients vary greatly in each profile. The distribution of $\mathrm{P}$ wave velocity in each profile is consistent with each other. The results show that the existence of a low velocity zone in the western area is related to the deposits of Neogene clastic sediments. In addition, from the three velocity profiles of the Chukou fault from east to west, we found that the velocity structures beneath the Chukou fault tend to dip toward the east. However, the distribution of earthquakes could not be equated with the Vp velocity. We also observe that a low Vp/Vs anomaly decreases with depth beneath the Central Mountain Range (CMR); however, the existence of high Vp anomalies is not obvious beneath the CMR. Right beneath the CMR, the existence of low Vp velocity is associated with the rock fragments of the CMR. Except for profile AA', we can observe a seismic zone dipping to the west and believe that this is about a blind fault zone. This phenomenon is worth investigating more regarding its geological implications beneath the Chia-Nan area.

Ultimately, we conclude that combining the $\mathrm{Vp}$ structure and $\mathrm{Vp} / \mathrm{Vs}$ ratio is useful in understanding tectonic structures and their evolutions.

\section{CONCLUSIONS}

In this study, we apply a damping least-square inversion method to investigate 3-D tomographic Vp structures and $\mathrm{Vp} / \mathrm{Vs}$ ratios of the crust and the upper mantle beneath Chia-Nan area using body waves travel time data. By using the time difference between observed $\mathrm{P}$ and $\mathrm{S}$ waves, we are able to invert the $\mathrm{Vp} / \mathrm{Vs}$ ratios. The advantage of this approach is to avoid calculating the $\mathrm{S}$ wave velocity directly. Since it is difficult to outline the variability of velocity structure beneath the surface from the $\mathrm{P}$ wave velocity, we use the $\mathrm{Vp} / \mathrm{Vs}$ ratio to correct the situation.

Our results indicate that we cannot only relocate earthquakes, but also can deduce the relationship between the seismicity and the regional geology structures. An additional finding was that most earthquakes occur in areas that have $\mathrm{Vp} / \mathrm{Vs}$ gradients that vary greatly. From our study, we infer that there may exist a west-dipping fault in the western Chukou fault. However, this inference needs further study.

Acknowledgments The authors thank two anonymous reviewers for their constructive comments and suggestions. 


\section{REFERENCES}

Asad, A. M., J. N. Louie, and S. K. Pullammanappallil, 1994: Combination of Linear Inversion and Nonlinear Optimization for Hypocenter and Velocity Estimation. Abstract, Am. Geophy. Union Fall Metting.

Chen, C. H., W. H. Wang, and Y. H. Yen, 1994: 3-D velocity structure in Taiwan: A tectonic implication of continent-arc collision. EOS Trans. Am, Geophys. Union., 75 , 645.

Chen, C. H.,W. H. Wang, and T. L. Teng, 2001: 3-D Velocity Structure Around the Source Area of The Chi-Chi Earthquake,1999, Taiwan: Before and After Mainshock. Bull. Seism. Soc. Am., 91, 1010-1027

Cheng, S. N., C. H. Chang, Y. T. Yeh, T. C. Shin, and M. T. Hsu, 1998: Seismicity of Taiwan from 1898 through 1997. Abstract, 1998 Western Pacific Geophy. Meeting, Taipei, Taiwan.

Cheng, W. B., 2000: Three-Dimensional Crustal Structure Around the Source Area the 1999 Chi-Chi Earthquake in Taiwan and Its Relation to the Aftershock Locations.TAO, 11, 643-660.

Christensen, N., 1996: Poisson's ratio in crustal seismology.J. Geophys. Res., 101, 31393156.

Eberhart-Phillips, D., 1990: Three dimensional P and S velocity structure in the Coalinga Region,California. J. Geophys. Res., 95, 15343-15363.

Eberhart-Phillips, D., and A. Michael, 1998: Seismotectonics of the Loma Prieta, California, region determined from three-dimensional $\mathrm{Vp}, \mathrm{Vp} / \mathrm{Vs}$, and seismicity.J. Geophys. Res., 103, 21099-21120.

Evans, J. R., D. Eberhart-Phillips, and C. H. Thurber 1994: User's manual for SIMULPS12 for imaging Vp and Vp/Vs: A derivate of the "Thurber" tomographic inversion SIMUL3 for local earthquakes and explosions, U.S. Geol. Surv. Open File Rept., 94-431.

Gentile, G. F., G. Bressan, L. Burlini, and R. De Franco, 2000: Three-dimensional Vp and $\mathrm{Vp} / \mathrm{Vs}$ models of the upper crust in the Friuli area (northeastern Italy). Geophys. J. Int. ,141, 457-478.

Graeber, F. M. and G. Asch, 1999: Three-dimentional models of P wave velocity and P-to-S velocity ratio in the southern central Andes by simultaneous inversion of local earthquake data. J. Geophys. Res., 104, 20237-20256.

Ho, C. S., 1986: A synthesis of the geologic evolution of Taiwan. Tectonophysics, 125, 1-16.

Husen, S., and E. Kissling, 2000: Local earthquake tomography between rays and waves: fat ray tomography. Phys. Earth Planet. Interiors, 3947, 1-21.

Lees, J. M., and C. E. Nicholson, 1993: Three-dimensional tomography of the 1992 southern California earthquake sequence: Constraints on dynamic earthquake rupture?.Geology, 21, 387-390.

Liu, C. S., I. L. Huang, and L. S. Teng, 1997: Structural features of south western Taiwan. Mar. Geol., 137, 305-319.

Johnson, P. A., and T. V. McEvilly, 1995: Parkfield seismicity: fluid-driven?.J. Geophys. Res., 100, 12937-12950. 
Ma, K. F., J. H. Wang, and D. Zhao, 1996: Three-dimensional seismic velocity structure of the crust and uppermost mantle beneath Taiwan. J. Phys. Earth, 44, 85-105.

Marianne, C. W., 1988: Three-Dimensional Vp/Vs Variations for the Coso Region, California. J. Geophys. Res., 93, 2047-2052.

Michelini, A., 1993: Testing the reliability of $\mathrm{Vp} / \mathrm{Vs}$ anomalies in traveltime tomography. Geophys. J. Int., 114, 405-410.

Miyamachi, H., K. Iwakiri, H. Yakiwara, K. Goto, and T. Kakuta, 1999: Fine structure of aftershock distribution of the 1997 Northwestern Kagoshima Earthquakes with a threedimensional velocity model. Earth Planets Space, 51, 233-246.

Musacchio, G., W. D. Moonly, J. H. Luetgert, and N. I. Christensen, 1997: Composition of crust in the Grenville and Appalachian Provinces of North America inferred from Vp/ Vs ratios. J. Geophys. Res., 102, 15225-15241.

Pavlis, G. L., and J. R. Booker, 1980: The mixed Discrete-Continuous Inversion Problem: application to the simultaneous determination of earthquake hypocenters and velocity structure. J. Geophys. Res., 85, 4801-4810.

Rau, R. J., and F. T. Wu, 1995: Tomographic imaging of lithospheric structures under Taiwan, Earth Planet. Sci. Lett., 133, 517-532

Roecker, S. W., Y. H. Yeh, and Y. B. Tsai, 1987: Three-dimensional P and S wave velocity structure beneath Taiwan: Deep structure beneath an arc-continent collision.J. Geophys. Res., 92, 10547-10570.

Stefano, R. D., C. Chiarabba, F. Lucente, and A. Amato, 1999: Crust and uppermost mantle structure in Italy from the inversion of P-wave arrival time: geodynamic implications. Geophys. J. Int., 139, 483-498.

Suppe, J., 1984: Kinematics of arc-continent collision, flipping of subduction, and back-arc spreading near Taiwan. Mem. Geol. Soc. China, 6, 21-34.

Thurber, C. H., 1983: Earthquake locations and three-dimension crustal structure in the Coyote Lake area, central California. J. Geophys. Res., 88, 8226-8236.

Thurber, C. H., and S. R. Atre, 1993: Three-dimensional Vp/Vs variations along the Loma Prieta repture zone. Bull. Seism. Soc. Am., 83, 717-736.

Toomey, D. R., and G. R. Foulger, 1989: Tomographic Inversion of Local Earthquake Data From the Hengill-Grensdalur Central Volcano Complex, Iceland.J. Geophys. Res., 94, 17497-17510.

Um, J., and C. Thurber, 1987: A fast algorithm for two-point seismic ray tracing. Bull. Seism. Soc. Am., 77,972-986.

Walck, M. C. (1988). Three-Dimensional Vp/Vs Variation for the Coso Region, California.J. Geophys. Res., 93, 2047-2052.

Wang, W. H. and C. H. Chen, 2001: Static stress transferred by the 1999 Chi-Chi, Taiwan, earthquake: Effects on the stability of the surrounding fault systems and aftershock triggering with a 3D fault-slip model. Bull. Seism. Soc. Am., 91, 1041-1052.

Wu, F. T., R. J. Rau, and D. Salzberg, 1997: Taiwan orogeny: thin-skinned or lithospheric collision? Tectonophysics, 274, 191-220. 
Zhao, D., and H. Kanamori, 1995: The 1994 Northridge earthquake: 3-D crustal structure in the rupture zone and its relation to the aftershock location and mechanisms. Geophys. Res. Lett., 22, 763-766.

Zhao, D., and H. Negishi, 1998: The 1995 Kobe earthquake: seismic image of the source area and its implications for the rupture nucleation. J. Geophys. Res., 103, 9967-9986. 